\title{
VEGF-C and VEGF-D expression is correlated with lymphatic vessel density and lymph node metastasis in oral squamous cell carcinoma: Implications for use as a prognostic marker
}

\author{
TSUYOSHI SUGIURA*, YOSHIKO INOUE*, RYOSUKE MATSUKI, KOTARO ISHII, \\ MIHO TAKAHASHI, MASAKAZU ABE and KANEMITSU SHIRASUNA \\ Department of Oral and Maxillofacial Surgery, Graduate School of Dental Science, \\ Kyushu University, Higashi-ku, Fukuoka 812-8582, Japan
}

Received September 17, 2008; Accepted November 29, 2008

DOI: 10.3892/ijo_00000193

\begin{abstract}
The prognosis of patients with oral squamous cell carcinoma (SCC) is influenced by the presence of lymph node metastasis. In this study, we analyzed the relationship between lymphangiogenesis and the expression of VEGF-C and VEGF-D in association with lymph node metastasis in oral SCC. Oral SCC biopsy specimens (160 cases) were examined for lymphatic vessel density (LVD) and the expression of VEGF-C and VEGF-D immunohistochemically. The levels of VEGF-C and VEGF-D expression and LVD were significantly associated with lymph node metastasis $(p<0.001)$. The expression of VEGF-C and VEGF-D increased the LVD significantly $(p<0.001)$. Multivariate analysis showed that VEGF-C expression and LVD were significantly associated with lymph node metastasis $(\mathrm{p}<0.001)$. This study presents clinical evidence for the important roles of VEGF-C and VEGF-D in lymphangiogenesis and lymphatic metastasis of oral SCC, and suggests that VEGF-C or LVD can effectively predict lymphatic metastasis of oral SCC.
\end{abstract}

\section{Introduction}

Squamous cell carcinoma (SCC) is the most common malignant tumor of the oral cavity and head and neck. Oral SCC undergoes lymphatic metastasis, but not blood-borne metastasis, and metastasizes to the regional lymph nodes

Correspondence to: Dr Tsuyoshi Sugiura, Department of Oral and Maxillofacial Surgery, Graduate School of Dental Science, Kyushu University, 3-1-1 Maidashi, Higashi-ku, Fukuoka 812-8582, Japan E-mail: sugiura@dent.kyushu-u.ac.jp

${ }^{*}$ Contributed equally

Key words: oral squamous cell carcinoma, lymph node metastasis, VEGF-C, VEGF-D, lymphatic vessel density in $30-40 \%$ of cases. The patient prognosis depends on the presence of lymph node metastasis. However, little is known about the molecular mechanisms underlying lymph node metastasis in SCC of the oral cavity.

Lymphangiogenesis, the growth of new lymphatic vessels, is believed to underlie lymph node metastasis. The extent of regional lymph node metastasis is an important indicator of tumor aggressiveness and is a prognostic factor for patients with several kinds of carcinoma (1-3). Although much data exist on angiogenesis, few studies have reported on lymphangiogenesis as a prognostic factor for human neoplasms, and the correlation between lymphatic vessel density (LVD) and metastasis to the lymph nodes is controversial. This is partly due to a lack of reliable immunohistologic markers specific for lymphatic-specific proteins. Recently, however, several lymphatic vessel-specific markers have been identified, and podoplanin, lymphatic vessel endothelial HA receptor-1 (LYVE-1), prox-1, and M2A were shown to be useful markers for differentiating between lymphatic and blood vascular endothelium (4).

Vascular endothelial growth factor (VEGF), a member of the platelet-derived growth factor family, is a major inducer of angiogenesis and vessel permeability (5). Members of the VEGF family include VEGF-A (or vascular permeability factor), VEGF-B (or VEGF-related factor, VRF), VEGF-C (or VEGF-related protein, VRP), VEGF-D (or c-fos-induced growth factor), VEGF-E, and placenta growth factor (PIGF). Three VEGF tyrosine kinase receptors have been identified: VEGFR-1 (Flt-1), VEGF-2 (Flk-1, KDR), and VEGFR-3 (Flt-4). VEGF-C and VEGF-D are ligands for VEGFR-3, which is expressed exclusively in lymphatic endothelial cells (5). Recent reports have shown that the overexpression of VEGF-C or VEGF-D induces tumor lymphangiogenesis and promotes lymphatic metastasis in mouse tumor models (6). However, few clinical studies have investigated the association between the expression of VEGF-C and VEGF-D, and lymphangiogenesis and lymphatic metastasis. In this study, we investigated LVD immunohistochemically using a specific marker of lymphatic endothelium, M2A, in oral SCC tissues and analyzed its relationship with lymph node metastasis in association with the expression of VEGF-C and VEGF-D. 


\section{Patients and methods}

Patients and tumor specimens. This study was based on a retrospective cohort of 160 patients who had been diagnosed with primary oral SCC and treated at the Department of Oral and Maxillofacial Surgery, Kyushu University Hospital, Fukuoka, Japan, between 1989 and 1998. All the biopsies were obtained from the patients before any treatment was given. The clinicopathological information on each case, including age, gender, tumor size, nodal status, location, treatment, and the presence or absence of recurrence and metastasis, was obtained from patient files. Eighty-seven men and 73 women were involved; the median age was 64 years and it ranged from 24 to 94 . All patients were staged according to the 1997 UICC TNM Classification of Malignant Tumors (7). When cervical metastasis was doubted clinically, neck dissection was performed, and the metastases were diagnosed histologically.

Immunohistochemistry. The biopsy samples were fixed in $10 \%$ neutralized buffered-formalin. Consecutive $4-\mu \mathrm{m}$-thick sections were cut and deparaffinized with xylene, rehydrated in a graded alcohol series, and then used for the histopathological and immunohistochemical analysis. The grade of tumor differentiation was determined using the criteria proposed by the World Health Organization (8). The histological mode of invasion was classified according to Anneroth's classification (9).

To block endogenous peroxide activity, $3 \% \mathrm{H}_{2} \mathrm{O}_{2}$ was applied, and non-specific reactions were blocked with $1 \%$ bovine serum albumen (BSA) Tris- $\mathrm{HCl}$ buffer. The sections were incubated overnight at $4^{\circ} \mathrm{C}$ with the primary antibodies anti-human VEGF-C (H-190; Santa Cruz Biotechnology, Santa Cruz, CA, USA), anti-human VEGF-D (MAB286; R\&D Systems, Minneapolis, MN, USA), and D2-40 (M3619; Dako Cytomation, Carpenteria, CA, USA). Immunostaining was performed with the Envision system (Dako), in accordance with the manufacturer's instructions. The immunolocalization of the protein was visualized using Envision/AP polymer reagent (Dako) and alkaline phosphatase substrate (Dako). The sections were counterstained with $1 \%$ methyl green, dehydrated, cleared, and mounted. Negative control staining consisted of substituting non-immune goat serum for the primary antibodies. We evaluated the staining pattern of the indicated proteins at the invasive edge of the primary tumors for all specimens. The degree of staining of these proteins in SCC cells was classified into three groups: ++ , strong staining was seen in $>50 \%$ of tumor cells; + , moderate staining occurred in $>50 \%$ of tumor cells; and,$->50 \%$ of tumor cells showed faint or weak staining (Fig. 1). Two independent observers blinded to each patient's status scored the samples.

Lymphatic vessel density (LVD) was assessed under light microscopic examination of the D2-40-positive microvessels at the invasive edge of the primary tumors. To standardize the different conditions between specimens, D2-40-positive vessels were counted under a x100 field and divided by the tumor cluster-free area [number of lymph vessels/tumor-free area $\left(\mu \mathrm{m}^{2}\right)=\mathrm{LVD}$. The mean LVD from three fields was calculated.
Statistical analysis. Statistical analysis was performed with the statistical software package StatView 4.5 (Abacus Concepts, Berkeley, CA, USA). The degree of staining for these proteins in relation to various clinicopathological factors was assessed with the $\chi^{2}$ test. The factors related to LVD were identified using stepwise analysis. The survival rate was estimated with the Kaplan-Meier method and analyzed using the log-rank test. To define independent risk factors for prognosis, univariate and multivariate analysis were performed with a Cox proportional hazards model. Differences were considered significant when $\mathrm{p}<0.05$.

\section{Results}

Expression of VEGF-C and VEGF-D in oral SCC. We examined the expression of VEGF-C and VEGF-D proteins in oral SCC lesions using immunohistochemistry. Table I summarizes the clinicopathological data of the 160 cases and VEGF-C and VEGF-D immunoreactivity. VEGF-C and VEGF-D were localized in the cytoplasm and occasionally on the membrane of SCC cells. Intense VEGF-C and VEGF-D staining was observed on the membrane of SCC cells, especially at the invasive edge. In stromal cells around carcinoma nests, we could not find any VEGF-C or VEGF-D staining. Occasionally, VEGF-D was detected in vascular endothelial cells near the carcinoma nests (Fig. 1). The rate of positive expression of VEGF-C and VEGF-D was 50.6 and $58.1 \%$, respectively.

Association between VEGF-C or VEGF-D expression and clinicopathological features. The relationship between VEGF-C and VEGF-D staining intensity and clinicopathological factors was analyzed with the $\chi^{2}$ test (Table I). The staining intensity of VEGF-C and VEGF-D on SCC cells was significantly associated with lymph node involvement (both $\mathrm{p}<0.001$ ), while the intensity of VEGF-C and VEGF-D was not related to the pattern of invasion or clinical $\mathrm{T}$ stage.

Relationships of VEGF-C and VEGF-D with LVD. The relationship between lymphangiogenesis in the primary tumor and lymph node metastasis was examined using the lymphatic vessel density (LVD) with D2-40 (Fig. 2). The LVD ranged from 0 to 20 (mean \pm SD 4.89 \pm 4.32 ). Fig. 3 shows the correlation between lymph node metastasis and LVD. The mean LVD in the metastatic lymph node-negative group was significantly lower than that in the metastatic lymph node-positive group $(2.64 \pm 2.09$ and $8.18 \pm 4.64$, respectively; $\mathrm{p}<0.001)$. LVD was correlated with the expression of VEGF-C $(\mathrm{p}<0.001)$ or VEGF-D $(\mathrm{p}<0.001)$ at the invasive edge (Fig. 4A and $\mathrm{B}$ ). Furthermore, the simultaneous expression of VEGF-C and VEGF-D was significantly associated with lymphangiogenesis (Fig. 4C).

Correlation between VEGF-C or VEGF-D expression and survival time. To investigate whether VEGF-C or VEGF-D expression predicts the outcome in patients with oral SCC, Kaplan-Meier analysis of the overall (Fig. 5A) and diseasefree (Fig. 5B) survival times was performed. The survival time of patients with a VEGF-C- or VEGF-D-positive tumor 

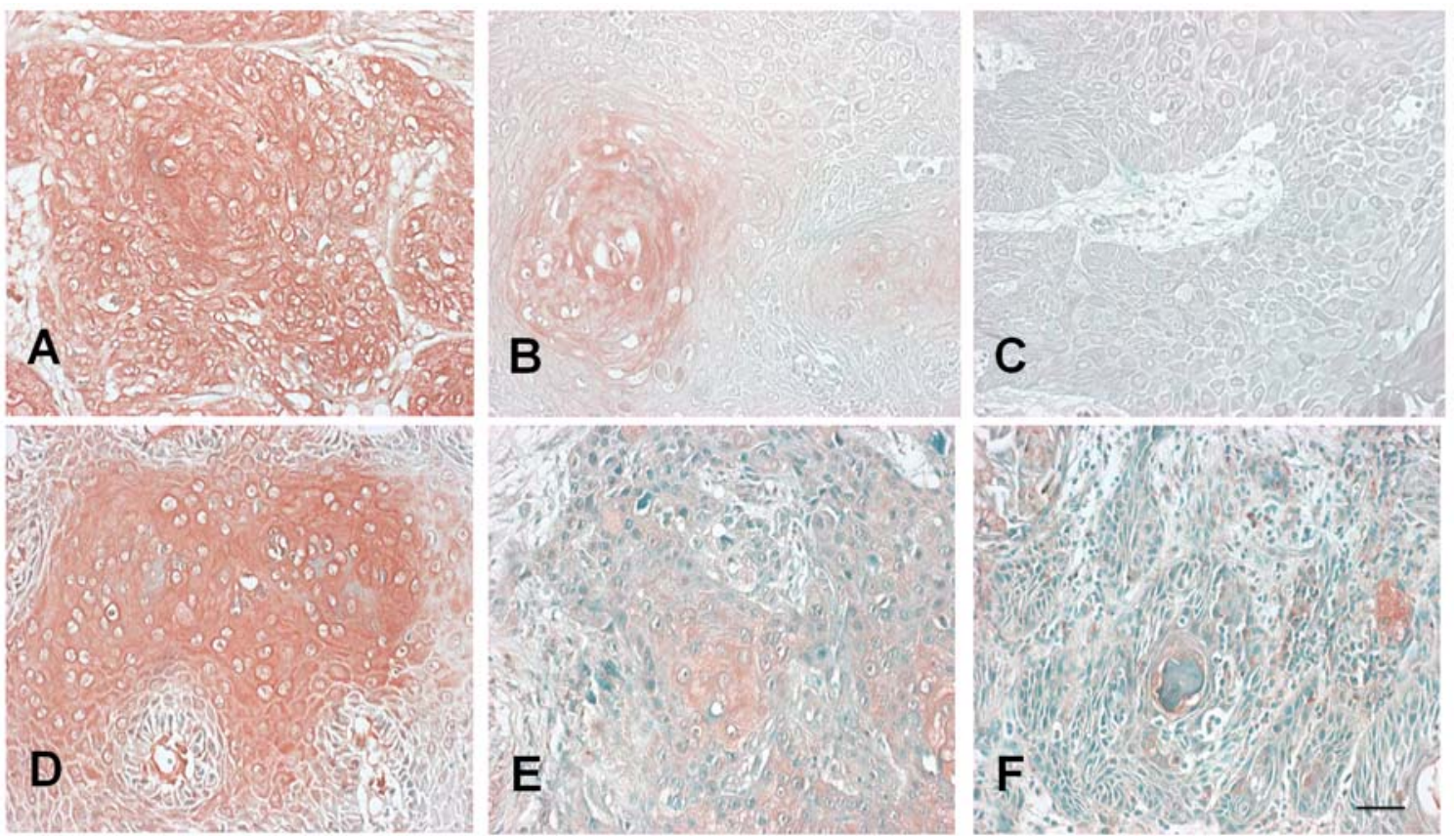

Figure 1. Immunohistochemical analysis of VEGF-C and VEGF-D expression in SCC tissue. Four- $\mu$ m-thick sections were used for the histopathological and immunohistochemical analysis as described in Patients and methods. The degree of staining of VEGF-C and VEGF-D in SCC cells was classified into three groups: ++ , strong staining was seen in $>50 \%$ of tumor cells; + , moderate staining occurred in $>50 \%$ of tumor cells; and -, $>50 \%$ of tumor cells showed faint or weak staining. Photographs represent tissue staining patterns of each group. (A-C) VEGF-C; (D-F) VEGF-D; (A and D) (++); (B and E) (+); (C and F) (-). Bar, $100 \mu \mathrm{m}$.
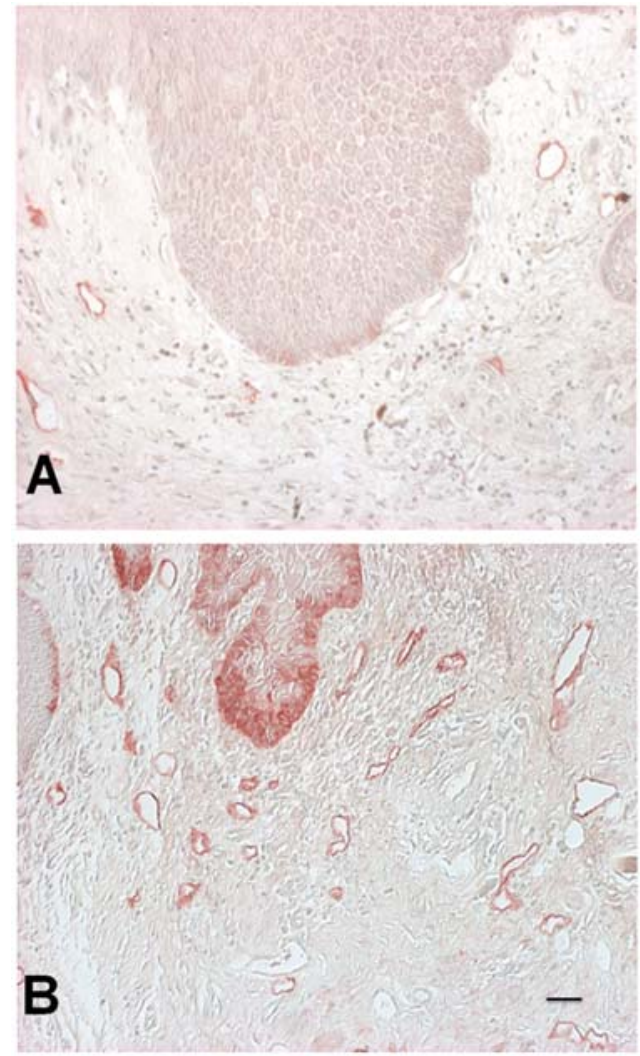

Figure 2. Immunohistochemical D2-40 staining in SCC tissue. Paraffin sections including tumor border were immunostained with anti-D2-40 antibody as described in Immunohistochemistry. Lymphatic vessels were assessed under light microscopic examination of the D2-40-positive microvessels at the invasive edge of the primary tumors. Bar, $100 \mu \mathrm{m}$. (A) Lymph node metastasis-negative; (B) Lymph node metastasis-positive cases.

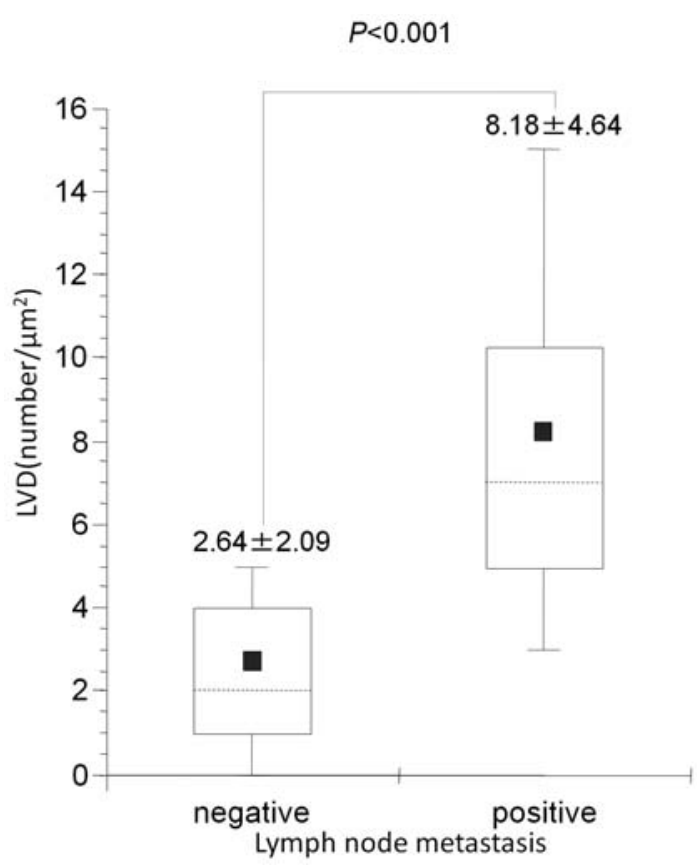

Figure 3. Correlation between lymph node metastasis and LVD. The correlation between lymph node metastasis and LVD is shown by box and whisker plot. The horizontal broken lines are the median LVD values. The vertical bars indicate the range and the horizontal boundaries of the boxes represent the first and third quartiles. The mean LVD values are indicated by closed squares and the figure indicates the value $\pm \mathrm{SD}$.

was significantly less than that of the negative counterpart (both $\mathrm{p}<0.05$ ). The survival time of patients with a VEGF-Cpositive and VEGF-D-negative tumor was significantly less 
Table I. Relation of immunoreactivity of VEGF-C and VEGF-D to clinicopathological factors.

\begin{tabular}{|c|c|c|c|c|c|c|c|c|c|}
\hline \multirow[b]{2}{*}{ Factor } & \multirow[b]{2}{*}{ Case } & \multicolumn{3}{|c|}{ VEGF-C expression } & \multirow[b]{2}{*}{ P-value } & \multicolumn{3}{|c|}{ VEGF-D expression } & \multirow[b]{2}{*}{ P-value } \\
\hline & & - & + & ++ & & - & + & ++ & \\
\hline \multicolumn{10}{|l|}{ Age } \\
\hline$<65$ & 81 & 44 & 28 & 9 & \multirow[t]{2}{*}{ NS } & 43 & 23 & 15 & \multirow[t]{2}{*}{ NS } \\
\hline$\geq 65$ & 79 & 42 & 25 & 12 & & 34 & 29 & 16 & \\
\hline \multicolumn{10}{|l|}{ Sex } \\
\hline Male & 87 & 46 & 28 & 15 & \multirow[t]{2}{*}{ NS } & 41 & 31 & 36 & \multirow[t]{2}{*}{ NS } \\
\hline Female & 73 & 40 & 25 & 16 & & 36 & 21 & 42 & \\
\hline \multicolumn{10}{|l|}{ Clinical Stage } \\
\hline $\mathrm{T} 1$ & 31 & 23 & 6 & 2 & \multirow[t]{4}{*}{ NS } & 18 & 6 & 7 & \multirow[t]{4}{*}{$\mathrm{NS}$} \\
\hline $\mathrm{T} 2$ & 75 & 36 & 29 & 10 & & 35 & 23 & 17 & \\
\hline $\mathrm{T} 3$ & 26 & 10 & 11 & 5 & & 11 & 12 & 3 & \\
\hline $\mathrm{T} 4$ & 28 & 17 & 7 & 4 & & 13 & 11 & 4 & \\
\hline \multicolumn{10}{|l|}{ Tumor site } \\
\hline Buccal mucosa & 18 & 13 & 4 & 1 & \multirow[t]{6}{*}{$\mathrm{NS}$} & 10 & 6 & 2 & \multirow[t]{6}{*}{ NS } \\
\hline Upper gingiva & 23 & 13 & 7 & 3 & & 14 & 5 & 4 & \\
\hline Lower gingiva & 41 & 17 & 20 & 4 & & 17 & 14 & 10 & \\
\hline Tongue & 65 & 34 & 18 & 13 & & 28 & 23 & 14 & \\
\hline Oral floor & 12 & 9 & 3 & 0 & & 7 & 4 & 1 & \\
\hline Lip & 1 & 1 & 0 & 0 & & 1 & 0 & 0 & \\
\hline \multicolumn{10}{|c|}{ Lymph node involvement } \\
\hline Positive & 65 & 12 & 35 & 18 & \multirow[t]{2}{*}{$<0.001$} & 12 & 32 & 21 & \multirow[t]{2}{*}{$<0.001$} \\
\hline Negative & 95 & 74 & 18 & 3 & & 65 & 20 & 10 & \\
\hline \multicolumn{10}{|c|}{ Tumor differentiation } \\
\hline Early invasive & 8 & 7 & 1 & 0 & \multirow[t]{3}{*}{ NS } & 4 & 2 & 2 & \multirow[t]{3}{*}{$\mathrm{NS}$} \\
\hline Well & 103 & 58 & 32 & 13 & & 51 & 33 & 19 & \\
\hline Moderate/poorly & 49 & 21 & 21 & 7 & & 22 & 17 & 10 & \\
\hline \multicolumn{10}{|l|}{ Pattern of invasion } \\
\hline 1 & 10 & 9 & 1 & 0 & \multirow[t]{4}{*}{ NS } & 9 & 1 & 0 & \multirow[t]{4}{*}{ NS } \\
\hline 2 & 20 & 12 & 7 & 1 & & 12 & 5 & 3 & \\
\hline 3 & 87 & 49 & 29 & 9 & & 40 & 28 & 19 & \\
\hline 4 & 43 & 16 & 16 & 11 & & 16 & 18 & 9 & \\
\hline
\end{tabular}

NS, not significant. Significant, $\mathrm{p}<0.050$.

than that of patients with tumors that were both VEGF-Cand VEGF-D-negative ( $\mathrm{p}<0.05 ;$ Fig. 5).

Logistic regression analysis of the predictive factors for lymph node metastasis. To examine the significance of the predictive factors for lymph node metastasis, a logistic regression analysis was performed (Table II). A univariate analysis showed that VEGF-C, VEGF-D, LVD, and the pattern of invasion were related to lymph node metastasis. Multivariate analysis showed that VEGF-C expression $(\mathrm{p}<0.001)$ and LVD $(\mathrm{p}<0.001)$ were significantly associated with lymph node metastasis. VEGF-C expression had the highest odds ratio (5.450) among the predictive factors.

\section{Discussion}

The intravasation of tumor cells into lymphatic vessels is one of the first steps in lymphatic metastasis. Lymphangiogenesis around solid tumors might promote lymphatic metastasis by providing a larger target for the intravasation of tumor cells.

Several specific markers for detecting lymphatic endothelium have been proposed, including VEGFR3, podoplanin, 

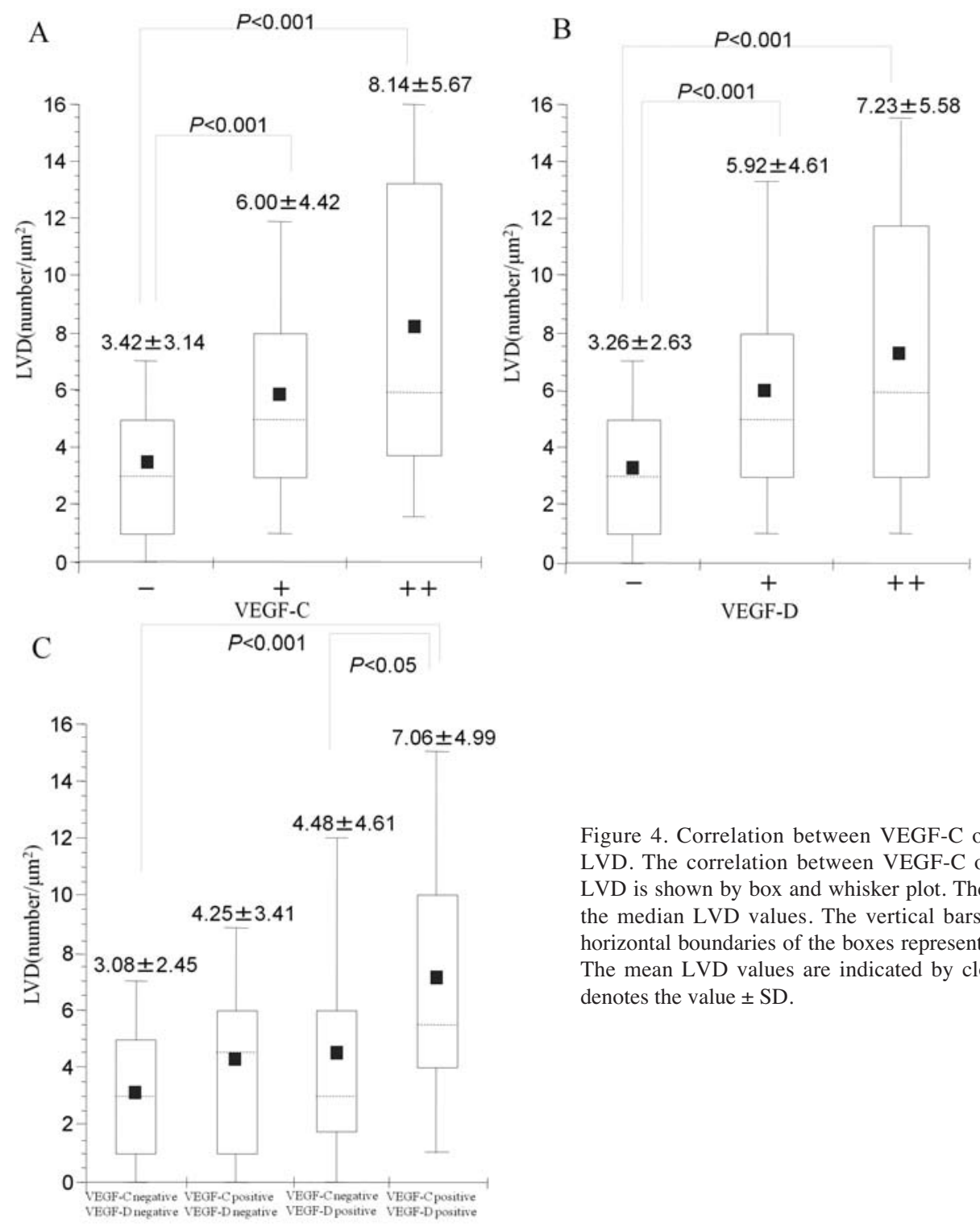

Figure 4. Correlation between VEGF-C or VEGF-D expression and LVD. The correlation between VEGF-C or VEGF-D expression and LVD is shown by box and whisker plot. The horizontal broken lines are the median LVD values. The vertical bars indicate the range and the horizontal boundaries of the boxes represent the first and third quartiles. The mean LVD values are indicated by closed squares and the figure denotes the value $\pm \mathrm{SD}$

Table II. Logistic regression analysis of predictive factors for lymph node metastasis.

\begin{tabular}{|c|c|c|c|c|c|c|}
\hline & \multicolumn{3}{|c|}{ Univariate analysis } & \multicolumn{3}{|c|}{ Multivariate analysis } \\
\hline & Odds ratio & $95 \% \mathrm{CI}$ & P-value & Odds ratio & $95 \% \mathrm{CI}$ & P-value \\
\hline \multicolumn{7}{|l|}{ VEGF-C expression } \\
\hline Negative vs. positive & 8.259 & $4.282-15.920$ & $<0.001$ & 5.450 & $2.030-14.541$ & $<0.001$ \\
\hline \multicolumn{7}{|l|}{ VEGF-C expression } \\
\hline Negative vs. positive & 3.829 & $2.342-6.265$ & $<0.001$ & 1.598 & $0.672-3.801$ & 0.289 \\
\hline Lymph vessel density & 1.809 & $1.487-2.201$ & $<0.001$ & 1.967 & $1.512-2.557$ & $<0.001$ \\
\hline \multicolumn{7}{|l|}{ Histological grade } \\
\hline \multicolumn{7}{|l|}{ Early invasive } \\
\hline Well & 1.953 & $1.065-3.577$ & 0.030 & 2.325 & $0.778-6.956$ & 0.131 \\
\hline \multicolumn{7}{|l|}{ Moderate/poorly } \\
\hline \multicolumn{7}{|l|}{ Mode of invasion } \\
\hline $1,2,3,4$ & 2.930 & $1.736-4.945$ & $<0.001$ & 2.567 & $1.092-6.035$ & 0.031 \\
\hline
\end{tabular}


A
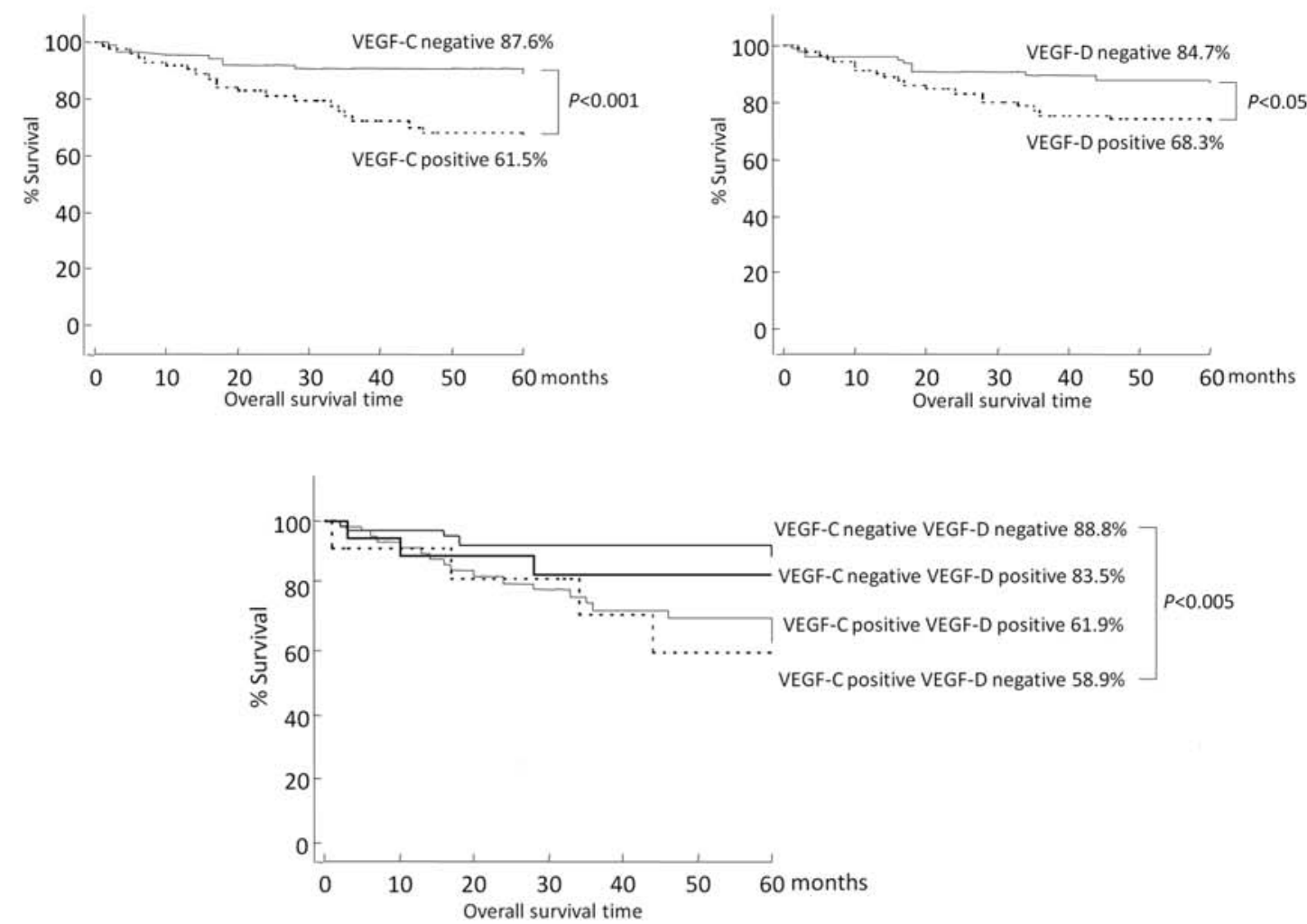

B
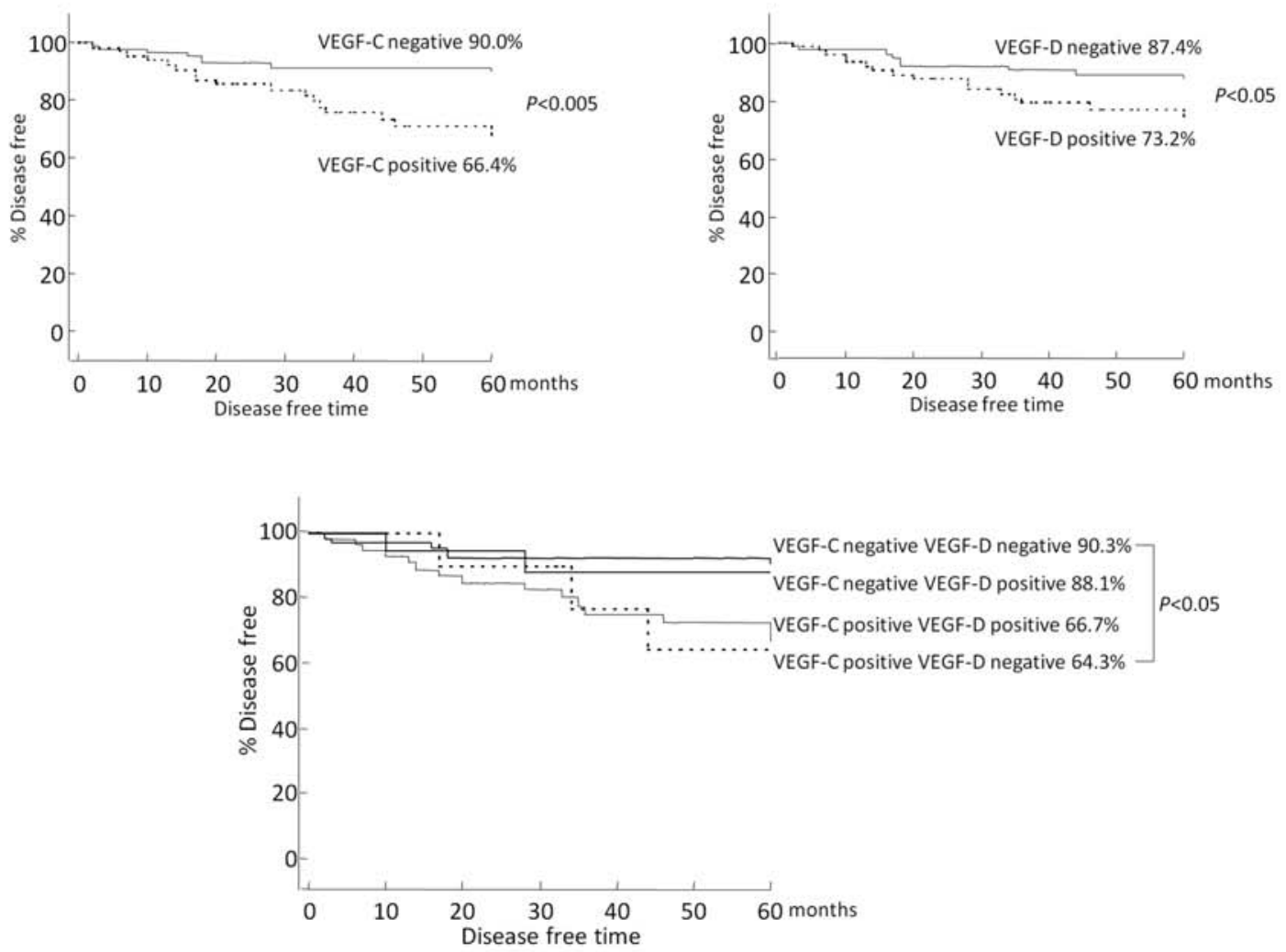

Figure 5. Kaplan-Meier survival analysis. The survival rate was estimated with the Kaplan-Meier method and analyzed using the log-rank test. The overall (A) and disease-free (B) survival of patients with tumors that were both VEGF-C- and VEGF-D-positive was significantly shorter than that of patients with tumors that were both VEGF-C- and VEGF-D-negative.

lymphatic vessel endothelial HA receptor-1 (LYVE-1), and Prox-1. Using these markers, the presence of intratumoral and peritumoral lymphatic vessels has been shown in many types of carcinoma (10-12). In addition to these, M2A, a 40-kDa 
O-linked sialoglycoprotein, was recently found to be expressed specifically on the endothelium of lymphatic vessels (13). D2-40, a monoclonal antibody against M2A, specifically immunolocalizes M2A on lymphatic vessels; its selectivity and specificity are quite reliable and it does not overlap the immunostaining reactivity of anti-CD34 antibody, a specific monoclonal antibody for vascular endothelium (14). Therefore, we used D2-40 to detect lymphatic vessels. As a quantitative indicator of lymphangiogenesis, we used the lymphatic vessel density (LVD) and analyzed its relationship to metastasis. The LVD was significantly correlated with lymph node metastasis $(\mathrm{p}<0.001)$.

The vascular endothelial growth factor (VEGF) family consists of hypoxia-inducible angiogenic factors that are found on the vascular endothelium (5). In the VEGF family, VEGF-C and VEGF-D are reported to be lymphangiogenic factors in experimental models (15). Lymphangiogenesis stimulated by VEGF-C and VEGF-D increases the potential for lymphatic metastasis of cancer, and several clinical studies have documented a correlation between the levels of VEGF-C and VEGF-D expression and lymphatic metastasis in cancer patients. Specifically, VEGF-C has been shown to be related to lymphatic metastasis in gastric (16), breast (17), thyroid (18), prostate (19), esophageal (20), and colorectal (21) carcinomas. In contrast, the relationship between VEGF-D and lymphatic metastasis is controversial; for example, VEGF-D is downregulated in many types of carcinoma tissue $(22,23)$. When we analyzed the association between VEGF-C and VEGF-D expression and lymph node metastasis in oral SCC statistically, both VEGF-C and VEGF-D were significantly correlated with lymph node metastasis $(p<0.001)$, suggesting the molecular importance of VEGF-C and VEGF-D in oral SCC metastasis. This result is in accordance with other reports on head and neck cancer (24).

The molecular mechanisms of the lymphatic metastasis of cancer are poorly understood. The important roles of VEGF-C and VEGF-D in lymphangiogenesis have been documented in animal models (25). For example, VEGF-C gene transduction induced the growth of functional lymphatic vessels in several different animal models (26). In another experimental tumor model, VEGF-D increased lymphatic vessel growth and lymphatic metastasis (25). In this study, we found strong correlations between lymphangiogenesis and both VEGF-C and VEGF-D in oral SCC patients. The co-expression of VEGF-C and VEGF-D is significantly related to lymphangiogenesis (Fig. 4). As we predicted, lymphangiogenesis (LVD) was strongly correlated with lymphatic node metastasis in oral SCC (Fig. 3). The logistic regression analysis revealed that VEGF-C is more significantly correlated with lymph node metastasis than VEGF-D (Table II). These findings suggest that VEGF-D is less important in lymphatic metastasis than VEGF-C, but is still necessary for oral SCC metastasis.

Many studies have suggested predictors of oral SCC, such as the pattern of invasion and the presence of certain matrix-degrading enzymes (27). However, these were not reliable predictive factors for lymphatic node metastasis in oral SCC. In this study, we demonstrated that VEGF-C and LVD are promising predictive factors for lymph node metastasis in oral SCC. Interestingly, VEGF-C expression was more significant in terms of lymphatic metastasis than LVD, suggesting that VEGF-C is involved not only in lymphangiogenesis, but also has other effects on lymphatic metastasis. For example, VEGF-C induces urokinase production by cancer cells, which accelerates plasmin-mediated matrix degradation around the tumor $(28,29)$. Furthermore, VEGF-C is primarily an angiogenic factor, which enables the cancer cells to grow and invade the surrounding tissue (2). Based on this information, it is possible that VEGF-C promotes cancer invasion through the surrounding tissues and induces lymphangiogenesis around the invasive edge, and results in the intravasation of the tumor into the lymphatic vessels.

In conclusion, this study presents clinical evidence for the important roles of VEGF-C and VEGF-D in lymphangiogenesis and lymphatic metastasis in oral SCC, and suggests that VEGF-C and LVD are useful for predicting lymphatic metastasis in oral SCC.

\section{Acknowledgements}

This work was supported by Grants-in-Aid from the Ministry of Education, Culture, Sports, Science, and Technology of Japan (to T. Sugiura).

\section{References}

1. Zeng Y, Opeskin K, Horvath LG, Sutherland RL and Williams ED: Lymphatic vessel density and lymph node metastasis in prostate cancer. Prostate 65: 222-230, 2005.

2. Hall FT, Freeman JL, Asa SL, Jackson DG and Beasley NJ: Intratumoral lymphatics and lymph node metastases in papillary thyroid carcinoma. Arch Otolaryngol Head Neck Surg 129: 716-719, 2003.

3. Straume O, Jackson DG and Akslen LA: Independent prognostic impact of lymphatic vessel density and presence of low-grade lymphangiogenesis in cutaneous melanoma. Clin Cancer Res 9: 250-256, 2003 .

4. Jackson DG: New molecular markers for the study of tumor lymphangiogenesis. Anticancer Res 21: 4279-4283, 2001.

5. Roy H, Bhardwaj S and Yla-Herttuala S: Biology of vascular endothelial growth factors. FEBS Lett 580: 2879-2887, 2006.

6. Kitadai Y, Kodama M, Cho S, Kuroda T, Ochiumi T, Kimura S, Tanaka S, Matsumura S, Yasui W and Chayama K: Quantitative analysis of lymphangiogenic markers for predicting metastasis of human gastric carcinoma to lymph nodes. Int J Cancer 115: 388-392, 2005.

7. Hermanek P and Sobin LH (eds): UICC: TNM Classification of Malignant Tumors. 4th edition. Springer-Verlag, Berlin, 1987.

8. Wasi PN, Cohen B, Luthra UK and Torloni H: Histological typing of oral and oropharyngeal tumors. In: WHO: International Histological Classification of Tumor, Geneva, 1971.

9. Anneroth G, Batsakis J and Luna M: Review of the literature and a recommended system of malignancy grading in oral squamous cell carcinomas. Scand J Dent Res 95: 229-249, 1987.

10. Beasley NJ, Prevo R, Banerji S, Leek RD, Moore J, van Trappen P, Cox G, Harris AL and Jackson DG: Intratumoral lymphangiogenesis and lymph node metastasis in head and neck cancer. Cancer Res 62: 1315-1320, 2002

11. Bono P, Wasenius VM, Heikkila P, Lundin J, Jackson DG and Joensuu H: High LYVE-1-positive lymphatic vessel numbers are associated with poor outcome in breast cancer. Clin Cancer Res 10: 7144-7149, 2004.

12. Zeng Y, Opeskin K, Baldwin ME, Horvath LG, Achen MG Stacker SA, Sutherland RL and Williams ED: Expression of vascular endothelial growth factor receptor-3 by lymphatic endothelial cells is associated with lymph node metastasis in prostate cancer. Clin Cncer Res 10: 5137-5144, 2004.

13. Franchi A, Gallo O, Massi D, Baroni G and Santucci M: Tumor lymphangiogenesis in head and neck squamous cell carcinoma: a morphometric study with clinical correlations. Cancer 101: 973-978, 2004. 
14. Xuan M, Fang YR, Wato M, Hata S and Tanaka A: Immunohistochemical co-localization of lymphatics and blood vessels in oral squamous cell carcinomas. J Oral Pathol Med 34: 334-339, 2005.

15. Al-Rawi MA, Mansel RE and Jiang WG: Molecular and cellular mechanisms of lymphangiogenesis. Eur J Surg Oncol 31: $117-121,2005$

16. Yonemura Y, Endo Y, Fujita H, Fushida S, Ninomiya I, Bandou E, Taniguchi K, Miwa K, Ohoyama S, Sugiyama K and Sasaki T: Role of vascular endothelial growth factor $\mathrm{C}$ expression in the development of lymph node metastasis in gastric cancer. Clin Cancer Res 5: 1823-1829, 1999.

17. Salven P, Lymboussaki A, Heikkila P, Jaaskela-Saari H Enholm B, Aase K, von Euler G, Eriksson U, Alitalo K and Joensuu $\mathrm{H}$ : Vascular endothelial growth factors VEGF-B and VEGF-C are expressed in human tumors. Am J Pathol 153: 103-108, 1998

18. Bunone G, Vigneri P, Mariani L, Buto S, Collini P, Pilotti S, Pierotti MA and Bongarzone I: Expression of angiogenesis stimulators and inhibitors in human thyroid tumors and correlation with clinical pathological features. Am J Pathol 155: 1967-1976, 1999.

19. Tsurusaki T, Kanda S, Sakai H, Kanetake H, Saito Y, Alitalo K and Koji T: Vascular endothelial growth factor-C expression in human prostatic carcinoma and its relationship to lymph node metastasis. Br J Cancer 80: 309-313, 1999.

20. Kitadai Y, Amioka T, Haruma K, Tanaka S, Yoshihara M, Sumii K, Matsutani N, Yasui W and Chayama K: Clinicopathological significance of vascular endothelial growth factor (VEGF)-C in human esophageal squamous cell carcinomas. Int J Cancer 93: 662-666, 2001.

21. Furudoi A, Tanaka S, Haruma K, Kitadai Y, Yoshihara M, Chayama K and Shimamoto F: Clinical significance of vascular endothelial growth factor-C expression and angiogenesis at the deepest invasive site of advanced colorectal carcinoma. Oncology 62: 157-166, 2002.
22. Niki T, Iba S, Tokunou M, Yamada T, Matsuno Y and Hirohashi S: Expression of vascular endothelial growth factors $\mathrm{A}, \mathrm{B}, \mathrm{C}$, and D and their relationships to lymph node status in lung adenocarcinoma. Clin Cancer Res 6: 2431-2439, 2000.

23. George ML, Tutton MG, Janssen F, Arnaout A, Abulafi AM, Eccles SA and Swift RI: VEGF-A, VEGF-C, and VEGF-D in colorectal cancer progression. Neoplasia 3: 420-427, 2001.

24. Shintani S, Li C, Ishikawa T, Mihara M, Nakashiro K and Hamakawa H: Expression of vascular endothelial growth factor A, B, C, and D in oral squamous cell carcinoma. Oral Oncol 40: $13-20,2004$

25. Stacker SA, Caesar C, Baldwin ME, Thornton GE, Williams RA, Prevo R, Jackson DG, Nishikawa S, Kubo H and Achen MG: VEGF-D promotes the metastatic spread of tumor cells via the lymphatics. Nat Med 7: 186-191, 2001.

26. Enholm B, Karpanen T, Jeltsch M, Kubo H, Stenback F, Prevo R, Jackson DG, Yla-Herttuala S and Alitalo K: Adenoviral expression of vascular endothelial growth factor-C induces lymphangiogenesis in the skin. Circ Res 88: 623-629, 2001.

27. Kyzas PA, Geleff S, Batistatou A, Agnantis NJ and Stefanou D Evidence for lymphangiogenesis and its prognostic implications in head and neck squamous cell carcinoma. J Pathol 206: 170-177, 2005.

28. Min HY, Doyle LV, Vitt CR, Zandonella CL, Stratton-Thomas JR, Shuman MA and Rosenberg S: Urokinase receptor antagonists inhibit angiogenesis and primary tumor growth in syngeneic mice. Cancer Res 56: 2428-2433, 1996.

29. Pepper MS, Ferrara N, Orci L and Montesano R: Vascular endothelial growth factor (VEGF) induces plasminogen activators and plasminogen activator inhibitor-1 in microvascular endothelial cells. Biochem Biophys Res Commun 181: 902-906, 1991. 